\title{
The case for calling alcohol a drug
}

\author{
Helen Macdonald head of education
}

The BMJ

The words that clinicians use matter. Professors Kypros Kypri and Jim McCambridge argue that the way we categorise these words is also important, particularly in relation to drug and addiction policy (doi:10.1136/bmj.k3944). Policy could deal with smoking, drugs, and alcohol separately. Or it could bring all addictive drugs together, including alcohol, among others.

"The clear identification of alcohol as a drug matters a great deal to the alcohol industry, and to society, because the policy implications are so important," they write. A recent systematic review and meta-analysis concluded that the level of alcohol consumption that minimised harm across health outcomes was zero. The wider people's access to alcohol, the greater its health and social harms.

Kypri and McCambridge compare the alcohol industry to the tobacco and gambling industries. "Profiting from addiction is a defining feature of these industries, along with obstructing the implementation of effective countermeasures," they write.

"Bringing alcohol, tobacco, and other drugs together in unified policies may support policy coherence, stimulate creative thinking about new countermeasures, and improve societal outcomes," they argue.

Is there much that clinicians can do about the politics behind policies? Probably not. But is it possible to adopt Kypri and McCambridge's suggestion in practice? Drinkers might feel unfairly judged if labelled as drug users, but pretending that alcohol is anything but a drug is perhaps doing them an equal disservice.

Clinicians might also find their own beliefs, behaviours, and experience of alcohol challenged by such a reclassification. Building on this theme, a feature this week asks whether doctors should share their personal experiences of healthcare with their patients (doi:10.1136/bmj.k4312). Read why some clinicians have chosen to share their stories while others haven't. The risks include hijacking a patient's consultation, influencing a patient in unpredictable ways, and making a patient feel awkward.

The potential benefit, however, is that we might just show that we are human. 